\title{
Improving coverage of medical research in a changing media environment
}

\author{
Julia Medew BA, Ray Moynihan PhD
}

- Cite as: CMAJ 2017 April 18;189:E551-2. doi: 10.1503/cmaj.161206

See related article at www.cmaj.ca/lookup/doi/10.1503/cmaj.160538

I

$\mathrm{n}$ the maelstrom of our changing media, some things will remain the same, particularly the need for reliable medical reporting to save us from drowning in misleading promotion. The evidence to date suggests much reporting overstates benefits of tests or treatments, plays down harms and fails to report important conflicts of interest..$^{1-3} \mathrm{~A}$ research article in CMAJ adds to that evidence base with some novel and disturbing findings about independent commenters being quoted in media reports. ${ }^{4}$ Genuinely independent and informed voices can help the public assess the merits and shortcomings of medical research. Meticulous attention to uncovering and reporting conflicts of interest is therefore vital to healthy medical journalism.

In their analysis of global media coverage of research studies published in high-impact general and internal medicine journals in 2013, Wang and colleagues ${ }^{4}$ found that only one in six media reports included comments from people who were independent of the study investigators. One in four of the independent commenters lacked relevant expertise, and one in three had financial conflicts of interest, most of which were not reported in the news stories. Perhaps most concerning of all, when the largely hidden conflicts of interest were congruent with the source research results, more than $90 \%$ of the comments were favourably disposed toward the results. Wang and colleagues' findings raise questions about systemic bias in media coverage.

In a landmark 2009 report on conflict of interest in medical research, education and practice, the Institute of Medicine noted the value of industry-professional collaborations. However, it argued that such collaborations were now so pervasive that the competing interests posed threats to professionals' judgments, research integrity, objective medical education and the very quality of health care. ${ }^{5}$

Key principles for covering health and medical news, promoted by the Association of Health Care Journalists, include investigating and reporting potential conflicts of interest, and seeking out "independent experts" to scrutinize claims and evaluate the quality of the research. ${ }^{6}$ As successive studies have suggested, journalists are either unaware of these principles or are regularly abandoning them.

\section{KEY POINTS}

- Independent voices are a critically important part of media coverage of medical research.

- Investigating and disclosing conflicts of interest are key principles of high-quality coverage.

- Changing media environments may lead to more "junk-food news."

- Strategies to include genuinely independent voices and improve coverage are needed.

Sixteen years ago, a study in the New England Journal of Medicine sounded a warning about how often media outlets failed to report on conflicts of interests. ${ }^{1}$ Focusing on coverage of three popular medications, the researchers found that many stories cited at least one expert or study with a financial tie to the drug's manufacturer but that only $39 \%$ of the stories mentioned that tie. Among television reports, the proportion mentioning the conflicts was zero. In 2003, a study in CMAJ of Canadian newspaper coverage of five new prescription drugs found that any mention of potential financial conflicts of interest was included for only $3 \%$ of interviewees, after exclusion of government and industry spokespeople. ${ }^{2}$ More recently, a study of coverage of pharmacogenetics in UK newspapers found that the majority of stories citing a scientific paper in which researchers had ties to industry failed to report that potential conflict. ${ }^{3}$ All three studies found that media reports tended to overstate benefits and downplay harms.

The great strength of the analysis by Wang and colleagues ${ }^{4}$ is its novel focus on the "independent experts" quoted in media reports, its assessment of just how independent and expert the commenters really were and whether their academic or financial conflicts of interest were reported in the news stories. The authors' findings suggest that many commenters are neither independent nor expert, which creates a hidden bias in media coverage.

As noted by the authors, a key limitation of the study is the strict criterion they used arbitrarily to define "expertise": commenters had to have authored five or more papers on the intervention/exposure 
or main outcome of the source research article in the previous five years. ${ }^{4}$ The reality of journalism is the difficulty, if not impossibility, of finding an accessible independent commentator with such expertise quickly. Moreover, we do not agree with the implicit suggestion that only experts are legitimate commenters. As Oxman and Guyatt pointed out in the early days of the evidence-based medicine revolution, expertise is to be valued, but experts have their own interests and do not always give the highest quality assessments of evidence. ${ }^{7}$

Although there are many examples of excellent journalism, medical or otherwise, one contemporary driver of poor quality might well be the collapse of the traditional media's business model, which has seen cuts to journalism jobs globally. As old media newsrooms have shrunk and editors have become increasingly fixated on getting clicks to draw funds from advertisers, media commenters have lamented the deterioration in quality. ${ }^{8}$ At the same time, new media proliferate online: a dubious story about the latest "breakthrough" can reach millions within minutes on social media.

Katharine Viner, editor-in-chief of The Guardian, noted in a recent essay that the shift away from public-interest journalism toward "junk-food news" suggests that we are in the midst of a fundamental change in the values of journalism. ${ }^{8}$ This shift is exacerbated by a move toward greater news consumption via social media, where algorithms provide users with more of what they think they want, reinforcing pre-existing beliefs, not challenging them. According to Viner's bleak assessment, instead of journalism striving to create an informed public as a civic good and democratic necessity, "it creates gangs, which spread instant falsehoods that fit their views, reinforcing each other's beliefs, driving each other deeper into shared opinions, rather than established facts." 8 There are likely as yet unknown benefits but also great risks to the quality of health news - and the people who read it in this new, rapidly changing world of media.

To improve news coverage of medical research, we need facts to challenge conventional, and inaccurate, beliefs about medicine. One could argue there has never been a more important time for clinicians, academics and journalists to work together on this endeavour. The call to develop and evaluate strategies to include more genuinely independent and informed commenters in the coverage of medical research is welcome, as part of wider efforts to make medical journalism healthier - in media new and old.

\section{References}

1. Moynihan R, Bero L, Ross-Degnan D, et al. Coverage by the news media of the benefits and risks of medications. N Engl J Med 2000;342:1645-50.

2. Cassels A, Hughes MA, Cole C, et al. Drugs in the news: an analysis of Canadian newspaper coverage of new prescription drugs. CMAJ 2003;168:1133-7.

3. Almomani B, Hawwa AF, Goodfellow NA, et al. Pharmacogenetics and the print media: What is the public told? BMC Med Genet 2015;16:32.

4. Wang MTM, Grey A, Bolland MJ. Conflicts of interest and expertise of independent commenters in news stories about medical research. CMAJ 2017;189: E553-9.

5. Institute of Medicine. Conflict of interest in medical research, education, and practice. Washington (DC): National Academies Press; 2009.

6. Statement of principles of the Association of Health Care Journalists. Columbia (MO): Association of Health Care Journalists. Available: http://healthjournalism. org/principles (accessed 2016 Oct. 3).

7. Oxman AD, Guyatt G. The science of reviewing research. Ann N Y Acad Sci 1993; 703:125-33.

8. Viner K. How technology disrupted the truth. The Guardian [London (UK)]; 2016 July 12.
Competing interests: Julia Medew is a health journalist enrolling in a PhD program investigating media coverage of diagnostics; Ray Moynihan is a researcher, author and former health journalist and has written on conflicts of interest.

This article was solicited and has not been peer reviewed.
Affiliations: Health section (Medew), The Age, Melbourne, Australia; Centre for Research in Evidence-Based Practice (Medew, Moynihan), Bond University, Robina, Australia; Sydney Medical School - Public Health (Moynihan), University of Sydney, Sydney, Australia
Contributors: Both authors were responsible for the concept and design of the article. Julia Medew wrote the first draft; both authors revised subsequent drafts, approved the final version to be published and agreed to act as guarantors of the work.

Correspondence to: Ray Moynihan, raymoynihan@bond.edu.au 